\title{
The Effect of Price on Fresh Vegetable Choices in Selected Markets of Morogoro Region, Tanzania
}

\author{
Robert Makorere*, Jackline Mariki, Samuel Mrisha \\ Department of Marketing and Entrepreneurship, Mzumbe University, Morogoro, Tanzania \\ Email address: \\ rfmakorere@mzumbe.ac.tz (R. Makorere) \\ ${ }^{*}$ Corresponding author
}

\section{To cite this article:}

Robert Makorere, Jackline Mariki, Samuel Mrisha. The Effect of Price on Fresh Vegetable Choices in Selected Markets of Morogoro Region, Tanzania. International Journal of Sustainable Development Research. Vol. 5, No. 3, 2019, pp. 79-90. doi: 10.11648/j.ijsdr.20190503.13

Received: January 13, 2019; Accepted: October 22, 2019; Published: October 31, 2019

\begin{abstract}
Absract: This study was aimed to examine the effect of market price on the choice of selected fresh vegetables across major markets in Morogoro Municipality. The study employed cross-sectional research design and convenience sampling method to obtain a sample size of 140 respondents. Data collected were analyzed using descriptive statistics and multinomial logit. Regarding variation of market price of the vegetables, findings had shown that, market price of fresh vegetables differed in the selected markets, whereby tomato at Mazimbu market had higher price (Tshs 1,340 per kg) than in Municipal market, with mean price of Tshs 1,125 per kg while it was Tshs 852 per $\mathrm{kg}$ for tomato at Mawenzi market. For onion, the mean price was Tshs 1,356 per $\mathrm{kg}$ in Municipal market, Tshs 1,138 per $\mathrm{kg}$ for Mazimbu market and Tshs 961 per kg at Mawenzi market. Cabbage had high mean price of Tshs 2,545 per kg in Municipal market, Tshs 1,725 per kg at Mazimbu market, and it was Tshs 963 per $\mathrm{kg}$ at Mawenzi market. Based on the findings, therefore, the effect of price on selecting fresh vegetable in the market show that customers with formal education who might prefer onion to cabbage would be expected to change by -0.4498 units (44.98\%). On the other hand, married customers less prefered onion to cabbage by 0.4975 units (49.75\%). In this study, the study recommends that the government should intervene specifically in improving institutional environment so as to reduce market uncetainity and risks of doing business in the fresh vegetable sub-sector. If this recommendation is implemented, then improvement in the fresh vegetable sub-sector would ultimately be realized.
\end{abstract}

Keywords: Price, Fresh Vegetable Choices, Selected Markets

\section{Introduction}

Agriculture plays an important role in the economic development of the Tanzanian's economy and rural livehoods, serving more than $90 \%$ of rural areas dwellers [33]. Agriculture in Tanzania contributes $30 \%$ to GDP, employing $80 \%$ of working population and $60 \%$ of all exports [13]. Agriculture perse does not only provides foods for entire population but also supply raw materials for industries. This makes Agriculture sector to remain as a backborn for a country's economy. Smallholder livehoods basically relied on crop and livestock production [5]. Furthermore, most of smallholder farmers are farming fresh vegetables in Tanzania.

Fresh vegetables are part of Agriculture which is cultivated mainly by smallholder farmers in rural and urban area in the country. Vegetables are source of vitamins, minerals and income to human being. It accounts for $44 \%$ of the total exports of Tanzania in year 2000 [19]. The exports contribute to National foreign earnings but also smallholder farmer's income. The fresh vegetable sub-sector in Tanzania is generally dominated by smallholder farmers who cultivate a farm of $0.1 \mathrm{Ha}$ up to $2 \mathrm{Ha}$. The productivity of fresh vegetable particularly onion is about 45 to 110 bags per acre, Egg plant is $200 \mathrm{Kg}$ per acre, Tomato is estimated to yield $600 \mathrm{Kg}$ per acre as well as $4500 \mathrm{Kg}$ per acre for Cabbage [27]. This neglect of traditional vegetables is not reasonable at all as these vegetables are especially important to the countries of sub-Saharan Africa, being better adapted to the environment than the introduced commercial vegetables.

In Tanzania, fresh vegetables are produced in rural and urban areas. However, the markets for fresh vegetables in the country are not lucrative to farmers due to precence of various factors including poor marketing price. This is 
because large percant of the fresh vegetables produced in the country is exchanged in local makets. Prices of fresh vegetables vary and change daily depending of markets [1]. This makes consumers to face difficulties in making choices or limit choice on fresh vegetable purchasing in the markets.. Therefore, the primary data collected for this study will be from the open commodity markets in Morogoro region. Understanding the consumer's choice and preferences at open market levels provides a starting point in understanding of fresh vegetables markets in Tanzania and elsewhere in Eastern and Southern Africa.

Despite the rapidly growing of fresh vegetables sub-sector in Tanzania, it is important to understand the connection between the price and choice of fresh vegetable that consumer prefers to consume. Since the sellers prefer to sell fresh vegetables that consumer opt to buy based on their choices. As the price of freshy vegetable is one the key driver that force consumer to make choices of fresh vegetable that fulfill the consumer needs [24]. With this, it is necessary to determine the influence of price on choices of fresh vegetables that consumer purchase $[6,33]$. However, despite several studies have been done on fresh vegetable sub-sector like the study done $[3,19,22,23]$ but still there is no studies have been done on the effects of price on vegetable choice among fresh vegetable consumers in Tanzania. So, there is knowledge gap which needs to be addressed by this study. By executing this study, the study expets to contribute knowledge on the effect of price on the selected fresh vegetable choices in the markets theoretically and empirically. Based on this view, it is therefore important to examine the effect of price on choice of fresh vegetable in Morogoro.

\section{Literature Review}

\subsection{Vegetable Production in Tanzania}

Tanzania has a large area suitable for horticultural cultivation but only a small portion of this is under cultivation. Regions with suitable conditions for vegetable cultivation are situated in the area of Morogoro, Tanga, Iringa, Moshi, Arusha and Mbeya. The region near Lake Tanganyika has potential for vegetable cultivation but no information is found that horticultural cultivation takes place there. Arusha and Tanga are situated in the north-eastern part and they are bordering Kenya. Mbeya and Iringa are located in the south and bordering to Malawi and Morogoro is situated west of Dar es Salaam. Regions were horticulture takes place are the coastal zone, central plateau, Lake Zone and the highlands.

\subsection{Theoretical Framework}

\subsubsection{Utility Maximization Theory}

The consumer satisfaction comes from welfare economics [11] where people aim at utility maximization of goods and services. Microeconomics consumer theory for individual preferences which present the way for transformations of assumptions about desires into a demand function expressing the action of the consumer in a given conditions provides the basis of economic valuation methods [25]. Choice agricultural products are usually derived under the basis of utility maximizing consumer and therefore uses random utility theory. In this view, the consumers chose options that provide them with the highest level of utility [8]. Based on this theory, the price of a commodity is determined by different factors including the price of the commodity itself, the individual's tastes and preference and prices of other related commodities.

In contrast, a group of vegetable farmers can choose to differentiate themselves by producing high-quality produce that will compete on value rather than producing the same standard product as most other farmers do. As a result, consumers choose them as preferred suppliers and consumers choose their products based on price [10]. This would increase the income of farmers and other players in the chain by producing good quality vegetables that could be sold at a premium in high-value markets. These farmers supply highvalue product, nature long term relationship between them and other buyers and sellers. They work together to reduce wastes, develop good trust between them and their buyers, share market information openly, and are assured of a good price for their produce from buyers since they have a good knowledge of the needs of consumers and other purchasers. The aim of such farmers is to maximize value rather than profit.

\subsubsection{Rational Choice Theory}

Rational choice theory is an economic principle that states that individuals always make prudent and logical decisions. These decisions provide people with the greatest benefit or satisfaction given the choices available and are also in their highest self-interest [17]. Most mainstream academic assumptions and theories are based on rational choice theory.

Rational choice theory assumes that all people try to actively maximize their advantage in any situation and therefore consistently try to minimize their losses [9]. The theory is based on the idea that all humans base their decisions on rational calculations, act with rationality when choosing, and aim to increase either pleasure or profit. Rational choice theory also stipulates that all complex social phenomena are driven by individual human actions. Therefore, if an economist wants to explain social change or the actions of social institutions, they need to look at the rational decisions of the individuals that make up the whole [36].

However, many economists do not believe in rational choice theory. Dissenters have pointed out that individuals do not always make rational utility-maximizing decisions. For example, the field of behavioral economics is based on the idea that individuals often make irrational decisions and explores why they do so. Additionally, Nobel laureate Herbert Simon proposed the theory of bounded rationality, which says that people are not always able to obtain all the information they would need to make the best possible 
decision [28]. Further, economist Richard Thaler's idea of mental accounting shows how people behave irrationally by placing greater value on some dollars than others, even though all dollars have the same value [12].

However, limitation rational choice theory is when individual choose more than one, it poses great difficulties for rational choice theory, which cannot explain why individuals who choose more than one product at a time.

\subsection{Conceptual Framework}

The concentual framework for this study is guided by the utility theory which explain the consumer behaviour. The utility theory depicts that consumer may prefer or choose certain vegetable because of price. So Price may influence consumers to make rational choice on vegetables. This confirm to the theory of demand which shows that small change of price of product (fresh vegetables) would lead to greater change of quantity demand by consumers, ceteris puribus [29]. Nevertheless, there are consumers who choose products because of quality. Theoretically, this implies that there consumers want to get maximum utility by consuming product with high quality.

However, the preference of consumer play roles in decision making. Such approaches are not able to capture in single market or product dependencies [21] due to demand relationships such as complementarity and substitution. Recently, new attempts have been made to employ multivariate logit structure to study price effect on product choice as well as market choice. Such application is fruitful because it does not only helps to understand true multicategory choice but also provides a basis to study effect of other marketing phenomena (such as price variation) in the selected markets and vegetable products in different market [19]. Due to interdependencies across market or product, consumer's response to both observed actual price and expected price. Price influence decision in market choice and product choice. Moreover, due to individual differences among items in one market in terms of product attributes and price.

On other hand, the law of supply states that a greater quantity of a vegetable product will be supplied at a higher price when other factors hold constant. As the price of vegetable product increases, producers are willing to produce more of the vegetable product, given that other factors remained constant [18]. The law of demand states that when prices rise, the quantity demanded falls and vice versa, holding other factors constant [30]. This also means that, when prices drop, demand will rise. Consumer makes purchasing decisions on price, if all other things are equal

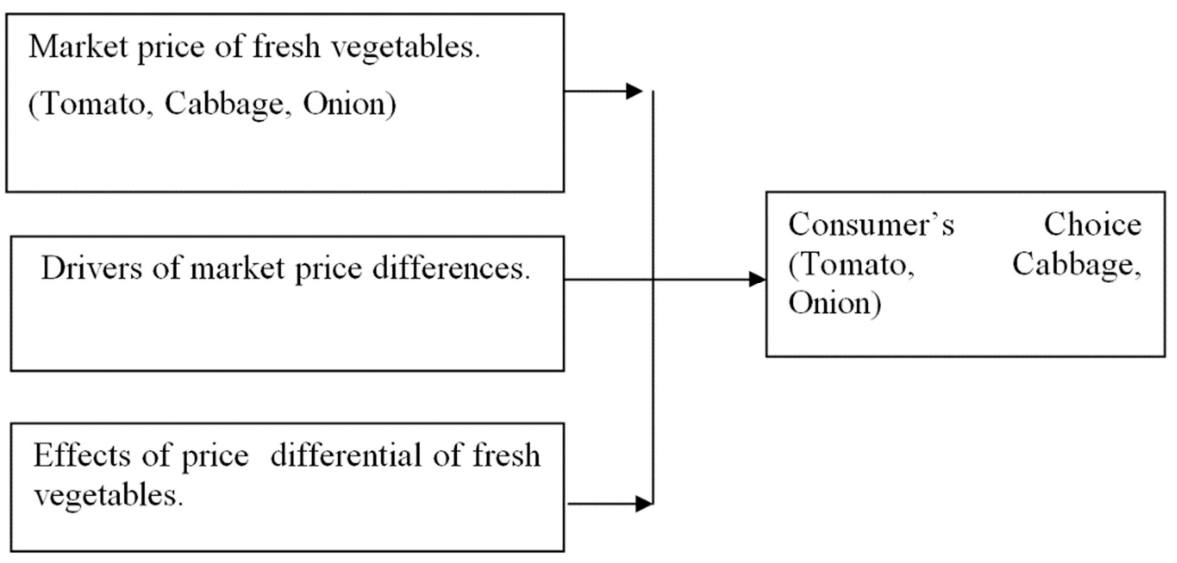

Figure 1. Conceptual Framework on the Effect of Price on Choice of Fresh Vegetable.

\section{Materials and Methods}

\subsection{Description of the Study Area}

The study was done in Morogoro Municipal and it covered three markets namely Mawenzi, Mazimbu, and Saba saba market. These markets were purposively selected because they sell more fresh vegetables than other markets in Morogoro Municipal.

On another hands, these markets have been selected because they are major source of food supplying (fresh vegetables) to the people reside in the municipal and those who came outside.

\subsection{Sampling and Data Collection Methods}

Before determining sample size, the study starts with identification of population of the study. According to [4] population can be defined as a group of individuals or items that share one or more characteristics of interest from which data can be gathered and analyzed. In view of that, the population for this particular research comprised consumers in Morogoro municipality consume onions, tomatoes, and cabbages. In this study, the population of the study was all consumers of fresh vegetables who visit to buy fresh vegetables at Mawenzi, Mazimbu and Saba saba market.

After determining the population of the study, selection of sample size was done. The selection of a sample from the population is commonly used in economics, marketing and other disciplines because of limitations of covering the whole population $[28,32]$. Sampling theory provides an opportunity to minimize cost and to achieve acceptable results $[24,26]$.

This study selected a sample size of 140 respondents who 
visited Mawenzi, Mazimbu and Saba saba markets to buy fresh vegetables in particular onions, tomatoes, and cabbages. The data on the effect of price on fresh vegetable choices in selected markets were collected basing on three fresh vegetables.

Despite the estimated sample size being 160, the study interviewed 140 respondents. This was because of limited time and budget constraints. Moreover, a sample size of 140 was sufficient, since according to [14] a sample size of 100 is sufficient to be used for most researches. Moreover, [14] uses a rule of thumb and argues that a sample size of more than 30; and less than 500 is sufficient [3] On the other hand, the study employed convenience sampling technique to arrive at a sample size of 140 respondents.

A convenience sampling technique was used to select consumers who visit to buy visit to fresh vegetables such as onions, tomatoes, and cabbages. The selection procedure was that consumers were selected based on their conveniently availability and accessible to the researcher.

A pilot survey to pre-test data collection instruments and to gain familiarization with the study areas was conducted in Mji mpya market in Morogoro Municipal. Using a closedand open-ended administered questionnaire, data was then collected on demographic characteristics; prices of fresh vegetables under study; types of fresh vegetables; and consumers' preferences for certain varieties, and average buying price per fresh vegetable in the agricultural season of 2018. Questionnaires were administered by two trained enumerators together with the researcher from June, 2018 to August, 2018.

\subsection{Analytical Techniques}

The study deployed the framework of utility theory as a guidline in addressing the the effect of price on fresh vegetable choices in the selected markets. The Choice method relies on random utility theory, in which consumers derive satisfaction not only from goods but also from attributes presented. An individual utility function is composed of a deterministic component $\left(\mathrm{V}_{\mathrm{ji}}\right)$ which can be calculated based on observed characteristics, and a stochastic error component $\left(\varepsilon_{\mathrm{ji}}\right)$ which is unobserved, so that

$$
U_{j i}=V_{j i}+\varepsilon_{j i}
$$

Where: $\mathrm{U}_{\mathrm{ji}}$ is the total utility derived from option by individual, $\mathrm{V}_{\mathrm{ji}}$ is the explainable component with the assigned attributes, and $\varepsilon_{\mathrm{ji}}$ is a stochastic component. In the utility function means that the probability that individual $\mathrm{j}$ selects option i can be expressed as the probability that the utility associated with option $i$ is greater than the utility of other options. Thus, the statistical model is driven by the probability that option i is selected, which is:

$$
\begin{array}{r}
P_{j i}=\operatorname{Pr}\left(U_{j i}>U_{j k}\right) \text { for all } \mathrm{k} \neq \\
\text { I; Which can be written as: } \\
P_{j i}=P_{j}\left[V_{j i}+\varepsilon_{j i}>V_{j k}+\varepsilon_{j k}\right]
\end{array}
$$

Imagine that the stochastic component or error terms are identically and independently distributed (IID) with a type I extreme value distribution the probability that option $\mathrm{I}$ is selected by individual $\mathrm{j}$ is:

$$
P_{j i}=\frac{\ell^{\beta_{i} x_{i}}}{\sum_{k=0}^{k} \ell^{\beta_{i} x_{i}}}
$$

Where $\beta_{\mathrm{j}}$ is a vector coefficients on each of the dependent variable $X$. Equation (iv) can be normalized to remove indeterminacy in the model by assuming that $\beta_{0}=0$ and the probabilities can be estimated as;

$$
\operatorname{Pr}\left(I=J / X_{i}\right)=\frac{\ell^{\beta_{i} x_{i}}}{I+\sum_{k=1}^{j} \ell^{\beta_{i} x_{i}}}, j=0,1 \ldots \ldots J, \beta_{0}=0
$$

Estimating eguation (v) yields $\mathrm{J}$ log-odd ratios:

$$
\ln \frac{P_{j i}}{P_{j k}}=X_{i}\left(\beta_{j}-\beta_{k}\right)=X_{i} \beta_{j}, \text { if } k=0
$$

The dependent variable is therefore the log of one alternative relative to the base alternative. To interpret the effects of explanatory variables on the probabilities, marginal effects are usually derived as [36].

$$
\delta_{j}=\frac{\delta P_{j}}{\delta X_{i}}=P_{j}\left[\beta_{j}-\sum_{K=0}^{J} P_{k} \beta_{k}\right]=P_{j}\left(\beta_{j}-\bar{\beta}\right)
$$

Therefore the full model is specified as follows:

$$
V_{i}=\beta_{i} X_{i}+\varepsilon_{j i}
$$

Where: $\beta_{\mathrm{i}}$ is a set parameter to be estimated, $\mathrm{V}_{\mathrm{i}}$ is a set of choice options, $X_{i}$ is a set of independent variables, and $\varepsilon_{\mathrm{i}}$ is an error term. This study selected Multinomial Logit Model (MNL) to examine the choice of alternative choice of vegetable. In this view, it involves multiple choices and it is easier to compute. The benefit of using a MNL model lays on its computational simplicity in calculating the choice probabilities that are expressible in analytical form [35].

Based on the aforementioned Logit Model (MNL) above, the study generally assumed that choice of vegetable (dependent variable) is influenced by certain intrinsic factors which include age of household head, gender of household head, marital status, education level, household size, income of households, price of cabbage, price of onion, price of tomato, quality of vegetable, and power of household.

Measurement of dependent variable: Dependent variable (DV) is choice of vegetable either cabbage, onion, or tomato. Based on this view above, data for estimating effect of price of fresh vegetable choice in this study were collected from the consumer visit the market.

Measurement of the Independent Variables: In this study, eleven independent variables were measured. Table 1 presents the summary of independent variables which influence fresh vegetable choices among consumers in Morogoro Municipal: 
Table 1. Summary of Independent Variables Influencing Choice Vegetable in Selected Markets of Morogoro, Tanzania.

\begin{tabular}{lll}
\hline Variable & Definitions & Unit of measurement \\
\hline $\begin{array}{l}\text { Dependent variable } \\
\text { Choice of vegetable }\end{array}$ & 1 if Tomato 2 if Cabbage 3 if Onion & Expected Sign \\
$\begin{array}{l}\text { Independent variables } \\
\text { Gender }\end{array}$ & Age of household head & Year \\
Marital status & 1 if respondent is Male, 0 otherwise & Dummy \\
Education Level & 1 if respondent married, 0 otherwise & Dummy \\
Household size & 1 if respondent has no formal education, 0 otherwise & Dummy \\
Income of household & Total number of individuals in household & Number \\
Price of Tomato & Average income per month & Tshs \\
Price of Cabbage & Price per Kg & Tshs \\
Price of Onion & Price per Kg & Tshs \\
$\begin{array}{l}\text { Quality of vegetable } \\
\text { Power of Household }\end{array}$ & Price per Kg & Tshs \\
\hline
\end{tabular}

\subsection{Description of Independent Variables}

Age: It is accounted as number of years the customer has spent in this world to the time where interview conducted. The age is measured in term of years of the customer spent since born to date. Children and youth are expected to consume more food or vegetable in order to improve their growing human body. However, a choice of vegetables that made by youth may be different from choice that made by elder customers. The youth as customers may prefers to buy luxury vegetables while elder may not prefers luxury vegetables. On the other hand, youth as customers may prefers to buy markets that far away from home while elder may not prefers market that located far away.

Gender: It is qualitative variable where it defines female or male that arise from biological different and responsibilities. The Gender is measured in dummy where male is coded as 1 and female is coded as 0 . A male is expected to consume more food or vegetable in order to improve their muscular body. However, a choice of vegetables that male by youth may be different from choice that made by female. A male as customers may prefers to buy luxury vegetables while female may not prefers luxury vegetables. On the other hand, a male as customers may prefers to buy markets that close enough from home while female may not prefers market that located far close enough [30].

Marital Status: It is accounted as a customer is married, wodow, single or divorced. The marital status is measured in dummy where for this case married customer was coded as 1 and 0 was coded as otherwise. A married customer is expected to consume purchases more food or vegetable in order to satify family or households. However, a choice of vegetables that made by married customer may be different from choice that made by non-married customers. The married customers may prefers to purchase non luxury vegetables while non married customer may prefers luxury vegetables [35]. On the other hand, married customers may prefers to buy markets that far away from home while married customers may not prefers market that located far away.

Education: It is accounted as whether a customer had informal education or formal education. The education is measured in dummy where customer spent at school. Customer with formal education was coded 1 and 0 was coded as otherwise (customer with no formal education). A customer with formal education is expected to purchases more food or vegetable in order to satify family or households. However, a choice of vegetables that made by customer with formal education may be different from choice that made by customers with informal education. The customer with informal education may prefers to purchase non luxury vegetables while customer with formal education may prefers luxury vegetables. On the other hand, customer with formal education may prefers to buy markets that far away from home while customers with informal education may not prefers market that located far away.

Income: It is accounted as value of the money that customer earned from the salary or wage. The income is measured in term of Tanzania shilling that customer earned per year. High income earners are expected to consume more food or vegetable in order to satisfy family members [26]. However, a choice of vegetables that made by customer based higher income earner may be different from choice that made by low income customers. The high icome customers may prefers to buy luxury vegetables while low income earner may not prefers luxury vegetables. On the other hand, higher income customers may prefers to buy markets that far away from home while low income customer may not prefers market that located far away.

Price of Tomato: It is accounted as value of the vegetable product sold at the market. The tomato price is measured in term of Tanzania shilling. Customer is expected to purchase more food or vegetable of low price in order to satisfy family members. However, a choice of vegetables that made by customer based higher price may be different from choice that made by customr to low price of vegetable. A customer may prefers to buy luxury vegetables with high price while customer may not prefers luxury vegetables with high price. On the other hand, customers may prefers to buy markets with higher price that far away from home while other customer may not prefers to buy vegetable with low price at market that located far away. 
Price of Cabbage: It is accounted as value of the vegetable product sold at the market. The Cabbage price is measured in term of Tanzania shilling. Customer is expected to purchase more food or vegetable of low price in order to satisfy family members. However, a choice of vegetables that made by customer based higher price may be different from choice that made by customr to low price of vegetable. A customer may prefers to buy luxury vegetables with high price while customer may not prefers luxury vegetables with high price. On the other hand, customers may prefers to buy markets with higher price that far away from home while other customer may not prefers to buy vegetable with low price at market that located far away.

Price of Onion: It is accounted as value of the vegetable product sold at the market. The Onion price is measured in term of Tanzania shilling. Customer is expected to purchase more food or vegetable of low price in order to satisfy family members. However, a choice of vegetables that made by customer based higher price may be different from choice that made by customr to low price of vegetable. A customer may prefers to buy luxury vegetables with high price while customer may not prefers luxury vegetables with high price. On the other hand, customers may prefers to buy markets with higher price that far away from home while other customer may not prefers to buy vegetable with low price at market that located far away.

Quality of Vegetable: It is accounted as whether a vegetable is of high quality or low quality. The quality is measured in dummy where for this case high quality was coded as 1 and 0 was coded as otherwise or low quality. A married customer is expected to consume purchases more food or vegetable of high quality or low quality in order to satify family or households. However, a choice on low quality vegetables that made by customer may be different from choice that made by customers who focus on low quality vegetable. The high quality may be prefered than of low quality vegetables while a customer may prefers low vegetables as well [27]. On the other hand, customers may prefers to buy markets of low quality vegetable or high quality vegetable that located far away from home while a customers also may not prefers market with high quality vegetable that located close enough to home site.

Household Size: It is accounted as countinous variable from number of people in the house. The household is measured in continuous value where total number of members in the house share the same dish. Household size as increase force to consume or purchases more food or vegetable in order to satify family or members. However, a choice of vegetables that made by based on large household size may be different from choice that made by small household size. The large household size may prefers to purchase non luxury vegetables while small household size may prefers luxury vegetables. On the other hand, large household size may prefers to buy from markets that close from home while small household size may not prefers market that located far away.

\subsection{Technical Considerations}

At the outset, this study assessed technical issue related to multicollinearity and Logit regression results validity. Multicollinearity was done to ensure that the results obtained are [34] truly representative for the researcher to be able to generalize the results. Therefore, the following examinations of technical considerations were done, namely multicollinearity and further testing of the overall relationship after model estimation.

Therefore, data collected using questionnaire was coded, entered in SPSS for data management and clearing. This involved careful validated and cleaned to ensure information is clearly present intended data for analysis. Thereafter, multinomial logit model was used in analyzing the data in this study.

\section{Findings and Discussion}

The paper aimed to assess the socio-economic factors influencing shifting from crop farming to woodlot farming in Mufindi district. Empirical evidences have been showing that majority of rural households own by crop farmers experience income poverty due to unfavorable socio-economic factors surrounding them compared with those farmers who had woodlot farms. As noted by [14], unfavourable socioeconomic factors are associated with high transaction costs, which would reduce income from exchanging. Therefore, socio-economic characteristics of woodlot farmers were reviewed prior the study applied logistic regression method to explain socio-economic factors that influence woodlot farming adoption as can be seen in the next sub-section below:

\subsection{Demographic Characteristics of Respondents}

The paper sees it is relevant to examine consumer's characteristics to determine features of the respondents included in the study. Empirical evidences have been showing that consumer's characteristic is one of the major factors that influence choice of vegetables of any actor [19, $22,34]$. In this view, the following are the intrinsic consumer characteristics assed in the paper:

Table 2. Demographic characteristics of respondents $(n=140)$.

\begin{tabular}{llll}
\hline Characteristic & Category & Frequency & Percent \\
\hline \multirow{2}{*}{ Gender } & Male & 60 & 43 \\
& Female & 80 & 57 \\
Age & Less than 40 Years (Youth Age) & 60 & 43 \\
& $41-54$ Years (Adult Age) & 62 & 44 \\
\hline
\end{tabular}




\begin{tabular}{llll}
\hline Characteristic & Category & Frequency & Percent \\
\hline & $55+$ Years (Old Age) & 18 & 13 \\
Education level & Never gone to school & 12 & 9 \\
& Primary education level & 59 & 42 \\
& Secondary education level & 58 & 41 \\
& Collage/University education level & 11 & 8 \\
Marital Status & Never married & 12 & 9 \\
& Married & 70 & 50 \\
& Divorced & 37 & 26 \\
Household Size & Widow & 21 & 15 \\
& 1 - 4 Family Members & 71 & 51 \\
& 5 - 8Family Members & 36 & 26 \\
\end{tabular}

\subsubsection{Gender of Respondents}

Table 2 shows that the study was not biased because gender balance i.e. male and female was seriously considered. For instance, the Table 2 shows that male were $60(43 \%)$ and female were $80(57 \%)$ participated in this study. This findings signify that female respondents were more active than male respondents in purchasing vegetables in selected markets. This means female were more active in purchasing vegetables for feeding the family in the households. Possibly female were the most active group in municipal because of the gender role of the female which fall into food preparation for family [22]. Notably male were not active in purchasing vegetable for family consumption due to culturally the male is always not active in purchasing vegetable for food preparation [18]. The present study conquers with findings [31] which found that female respondents play important in household food preparation.

\subsubsection{Age of Respondents}

The age of respondents was categorised into the following groups as can be seen in Table-2, less than 40 years, 41 to 54 years, and 55 years and above. According to Table 2, the highest age group is 41 - to 54 years which is equivalent to $62(44 \%)$ and the lowest age group $55+$ which is equivalent to $18(13 \%)$. This implying that most of the adulty people with age between 41 and 54 years purchase vegetables for house use from selected markets, although large population of Tanzania are youth the finding proven not more active. Possible explanation was that young people were not prefers to prepare their foods or vegetable foods but prefers to buy cooked foods [18]. Moreover, most of older people seems to depends on their sons and daughter for their foods and thus they were not responsible for purchasing vegetables for meal preparation.

\subsubsection{Education Level of Respondents}

The results in Table 2 show that $12(9 \%)$ respondents had non-formal education (Never gone to school), 59 (42\%) respondents had primary education, $58(41 \%)$ respondents had secondary education, and $11(8 \%)$ respondents had university or college education. Based on these findings, majority of vegetable buyers had primary education. However, the result was suprisingly since majority of respondents who fallen into primary education and secondary education were close. However, majority of respondents had primary education, followed by majority of respondents with secondary education. This was great for respondents to have knowledge in making appropriate choice of vegetables in selected markets.

\subsubsection{Marital Status of Respondents}

Results in Table 2 show that $12(9 \%)$ respondents were not married (never married), $70(50 \%)$ respondents were were married couple, $37(26 \%)$ respondents were divorced, and 21 $(15 \%)$ respondents were windowed. This results had shown that majority of respondents were married; and have great effects as married couples in the proper family management which yield close relationship among the family members than the rests such as single, widowed and divorced due to different in man power and decision making. This findings concur with the study done [18] that married coupled prefers to purchase vegetable and cook at home to enjoy with household member or family member unlike single person may not perefers to purchase vegetable for meal preparation at home.

\subsubsection{Household Size of the Respondents}

The results from Table-2 indicates that 71 (51\%) respondents interviewed were living in a household with less than 4 family members while 36 (26\%) respondents interviewed were living in a household of 5 to 8 people together, and $33(23 \%)$ respondents interviewed were living in the household of $9(23 \%)$ people together. The result indicates majority of the respondents had households of less tha people were living together and share the same dish in the family. This implies that as members in household increases, there is possibility of the household to purchase more vegetables of cheapest if their icome remain unchanged and not depends on their vegetable raised at home garden. This is to say lifestle of the most people in town had charged from large households to small size of households unlike in rural area where majority of households have many members in the households [23]. Further, [18] as life becomes so difficult, most of the households tune to have small household size which may be serviced by small family budget.

\subsection{The Drivers of Market Price Difference of Fresh Vegetable in the Selected Markets}

\subsubsection{Difference in Market Fees Paid by Vegetable Sellers}

Based on the findings, the findings indicated that $45 \%$ of 
respondents interviewed had pointed that high market fee paid by vegetable sellers in Mawenzi market while $7.9 \%$ of respondents interviewed had pointed that high market fee paid by vegetable sellers in Mazimbu market, and $47.1 \%$ of respondents interviewed had pointed that high market fee paid by vegetable sellers in Municipal market. Therefore, majority of respondents had pointed that high market fee paid by vegetable sellers in municipal market. This may be explained that municipal market positioned at the town centre compared to the rest of the market and had more customers visiting the market for acquiring the different human consubale products

\subsubsection{Difference Quality of Vegetable Produce}

Based on the findings, the findings have shown that $32.9 \%$ respondents had strongly agreed that difference quality of vegetable produce influence to the market price difference, $17.1 \%$ of respondents interviewed had agreed that quality of vegetable contributes to the market price difference, $21.4 \%$ of respondents interviewed had neutral response on either quality of vegetable contributes to the market price difference, $11.4 \%$ of respondents interviewed had disagreed that quality of vegetable contributes to the market price difference while $17.1 \%$ of respondents interviewed had strongly disagreed that quality of vegetable contributes to the market price difference. Based on this findings, therefore, majority of respondents had strongly agreed that quality of vegetable contributes to the market price difference.

\subsubsection{High Market Security Fee Brought Price Difference}

The study revealed that there are market security fees which are paid by the traders. In turn, this market cost has implication to the final selling price of vegetable to the final buyers (consumers). Based on the study interview, findings from the interview shown that $25.7 \%$ of respondents had strongly agreed that high Market security fee brought price difference while $19.3 \%$ of respondents interviewed had agreed that high Market security fee brought price difference meanwhile $13.6 \%$ of respondents interviewed had neutral response on either high Market security fee brought price difference, $17.9 \%$ of respondents interviewed had disagreed that high Market security fee brought price difference while $23.6 \%$ of respondents interviewed had strongly disagreed that high Market security fee brought price difference. Therefore, majority of respondents had strongly agreed that high Market security fee brought price difference.

\subsubsection{Market Location Contribute Price Difference}

Based on the study findings, the findings shows that market location and supporting business infrastructures have an influence on difference in the selected markets. This means market which is located far and connected to improper marketing infrastructures (roads, storage facilities, etc) obviously offer difference prices compared with the markets which is located in favourable location. This also has been shown by the interviewed respondents, for instance, $32 \%$ of respondents interviewed had strongly agreed that market location contribute price difference, $16 \%$ of respondents interviewed had agreed that market location contribute price difference, $11 \%$ of respondents interviewed had neutral response on either market location contribute price difference, $22 \%$ of respondents interviewed had disagreed that market location contribute price difference while $19 \%$ of respondents interviewed had strongly disagreed that market location contribute price difference. Therefore, majority of respondents had strongly agreed that market location contribute price difference.

\subsection{The Extent to Which Market Price of Fresh Vegetables Differs in the Selected Markets}

Under this study, the extent to which Market Price of Fresh Vegetables Differs in the Selected Markets was examined. To achieve this objective, the study examined each products, such as, tomato, cabbage, and onion as presented below in Tables 3, 4, and 5 .

Table 3. Average Price for Tomato in Selected Markets $(n=140)$.

\begin{tabular}{|c|c|c|c|c|}
\hline Variable & Mean & Std. Dev. & Minimum & Maximum \\
\hline Tomato Price at Municipal & 1125 & 390 & 450 & 2250 \\
\hline Tomato Price at Mawenzi & 852 & 124 & 450 & 1350 \\
\hline Tomato Price at Mazimbu & 1340 & 604 & 750 & 3450 \\
\hline
\end{tabular}

Based on this findings above, Table 3 indicates that mean price for Tomato was as high as Tshs 1340 per $\mathrm{kg}$ in Mazimbu market followed by Manispaa market with mean price of Tshs 1125 per $\mathrm{kg}$ of Tomato while the low mean price of Tshs 852 per $\mathrm{kg}$ for Tomato was recorded at Mawenzi market. Possible esxplanation was that mazimbu market is not located close to the town centre as the case of the other selected markets and supply for vegetables may be few not as many as in other selected markets. This may forced price of tomato to be higher than the rest of selected markets. The price for vegetable in selected market differs across the market as well as vegetable products (Tomato, Cabbage, Onion).

Table 4. Average Price for Cabbage in Selected Markets ( $n=140)$.

\begin{tabular}{lllll}
\hline Variable & Mean & Std. Dev. & Minimum & Maximum \\
\hline Cabbage Price at Municipal & 2545 & 919 & 500 & 6450 \\
Cabbage Price at Mawenzi & 963 & 225 & 600 & 1500 \\
Cabbage Price at Mazimbu & 1725 & 967 & 500 & 6450 \\
\hline
\end{tabular}


Based on this findings above, Table 4 shows that mean price for Cabbage was as high as Tshs 2545 per $\mathrm{kg}$ in Municipal market followed by Mazimbu market with mean price of Cabbage about Tshs 1725 per kg while the low mean price of Tshs 963 per $\mathrm{kg}$ was recorded at Mawenzi market. This implies that probably the supply of cabbage at municipal market was low than demand of cabbage at the market thus price was forced to raise up in comparison with the rest of selected markets.

Table 5. Average Price for Onion in Selected Markets $(n=140)$.

\begin{tabular}{lllll}
\hline Variable & Mean & Std. Dev. & Minimum & Maximum \\
\hline Onion Price at Municipal & 1356 & 367 & 800 & 2000 \\
Onion Price at Mawenzi & 961 & 226 & 500 & 1600 \\
Onion Price at Mazimbu & 1138 & 218 & 600 & 1700 \\
\hline
\end{tabular}

Based on this findings above, Table 5 depicts that mean price for Onion was as high as Tshs 1356 per kg in Municipal market followed by Mazimbu market with mean price of Tshs 1138 per kg of Onion while the low mean price of Tshs 961 per $\mathrm{kg}$ for Onion was recorded at Mawenzi market. Possibly it explained that higher price of onion at municipal market may be resulted from low supply of onion the market thus pressurize price to raise up.

\subsection{Multinomial Logit Analysis Results}

In this study, multinomial logit model was used in assessing the effect of price difference on fresh vegetable choice in the selected markets. The multinomial logit model output is shown in Table 6 as presented below:

Table 6. Multinomial Logit Model Estimation Results of Price Difference on Choice of Fresh Vegetable.

\begin{tabular}{|c|c|c|c|c|c|}
\hline \multirow{2}{*}{ Vegetable Choice } & \multirow{2}{*}{ Observed Variable } & \multirow{2}{*}{ Coefficient } & \multicolumn{3}{|l|}{ Robust } \\
\hline & & & Std. Err & $\mathbf{Z}$ & $\mathbf{P}>\mathbf{Z}$ \\
\hline \multirow{7}{*}{ Tomato } & Gender & 0.5971 & 0.7479 & 0.80 & 0.425 \\
\hline & Education & 0.2757 & 0.3783 & 0.73 & 0.466 \\
\hline & Marital status & 0.0602 & 0.3091 & 0.19 & 0.846 \\
\hline & Tomato Price & -0.8577 & 1.3334 & -0.64 & 0.520 \\
\hline & Cabbage Price & 0.2889 & 1.0620 & 0.27 & 0.786 \\
\hline & Onion Price & -1.1307 & 1.9676 & -0.57 & 0.566 \\
\hline & Constant & 9.4462 & 17.4431 & 0.54 & 0.588 \\
\hline \multirow[t]{4}{*}{ Cabbage } & & (base outcome) & (base outcome) & & \\
\hline & Gender & 0.5558 & 0.5679 & 0.98 & 0.33 \\
\hline & Education & -0.4498 & 0.2684 & -1.68 & 0.09 \\
\hline & Marital status & -0.4975 & 0.2656 & -1.87 & 0.06 \\
\hline \multirow[t]{4}{*}{ Onion } & Tomato Price & -0.9067 & 1.0168 & -0.89 & 0.37 \\
\hline & Cabbage Price & -0.2345 & 0.7857 & -0.30 & 0.77 \\
\hline & Onion Price & -3.9499 & 1.5426 & -2.56 & 0.01 \\
\hline & Constant & 37.6693 & 13.5068 & 2.79 & 0.01 \\
\hline
\end{tabular}

Based on the findings, Table 6 presents results of estimated multinomial logistic regression coefficients for the models. An important feature of the multinomial Logit model is that it estimates $\mathrm{k}-1$ models, where $\mathrm{k}$ is the number of levels of the outcome variable. In this instance, Stata was treating the cabbage as the referent group and therefore estimated a model for tomato relative to cabbage and a model for onion relative to cabbage. Therefore, since the parameter estimates are relative to the referent group, the standard interpretation of the multinomial Logit is that for a unit change in the predictor variable, the Logit of outcome relative to the referent group is expected to change by its respective parameter estimate (which is in log-odds units) given the variables in the model are held constant.

In this study, the analysis was done to examine the effect of price direffential on choice of fresh vegetable in selected market. The multinomial logit model was used for analysis with focus on variables intending to capture the effect gender, education, marital status, tomato price, cabbage price, onion price on choice vegetable (Tomato, Cabbage, Onion). The variables used for analysis are quantitative in nature and some independent variables were converted into dummy variables for capturing information that fall into qualitative.

\subsubsection{Tomato Relative to Cabbage}

Gender was positive and statistically insignificant at $10 \%$ level of significance with P-value 0.425 which greater than 0.1 level of significance. This is the multinomial logit estimate comparing gender for tomato relative to cabbage given the other factors in the model are held constant. The multinomial logit of gender for choosing tomato relatives to cabbage was 5971 units high for not preferring tomato to cabbage given all other factors in the model are held constant. In other words, a male was not more likely to prefer tomato relative to cabbage.

Education was positive and statistically insignificant at $10 \%$ level of significance with P-value 0.466 which greater than 0.1 level of significance. This is the multinomial logit estimate comparing customer with formal education to customer with no formal education for tomato relative to cabbage was 0.2757 given the other factors in the model are held constant. A customer with form education may prefers for tomato relative to cabbage would not be expected to decrease by 0.2757 units while holding all other factors in the model constant. In other words, customer for vegetable with formal education was not likely to prefer tomato relative over cabbage in given that all other factors 
remained constant.

Marital status was positive and statistically insignificant at $10 \%$ level of significance with P-value 0.846 which greater than 0.1 . Marital status was statistically insignificant. This is the multinomial logit estimate comparing married customer to unmarried customer for tomato relative to cabbage was 0.0602 , given the other factors in the model are held constant. The multinomial logit for married customer relatives to unmarried customer was 0.0602 units not more for preferring tomato to cabbage given all other factors in the model are held constant. In other words, married customer were not more likely than unmarried customer to prefer tomato relative to cabbage. A married customer was not likely to choose tomato relative to cabbage than unmarried customer.

Tomato price was negative and statistically insignificant at $10 \%$ level of significance with P-value 0.520 which greater than 0.1 level of significance. This is the multinomial logit estimate of price for tomato relative to cabbage was -0.8577 given the other factors in the model are held constant. If tomato price increases by $1 \%$, the multinomial log-odds of preferring for tomato relative to cabbage would not be expected to change by 0.8577 units while holding all other factors in the model constant.

Cabbage price was positive and statistically insignificant at $10 \%$ level of significance with P-value 0.786 which greater than 0.01 level of significance. This is the multinomial Logit estimate of cabbage price for tomato relative to cabbage was 0.2889 given the other factors are held constant. If price of cabbage was to increase by $1 \%$, the multinomial log-odds of preferring for tomato relative to cabbage would be expected to change by 0.2889 units while holding all other factors in the model constant.

Onion price was negative and statistically insignificant at $10 \%$ level of significance with P-value 0.566 which greater than 0.01 level of significance. This is the multinomial Logit estimate of onion price for tomato relative to cabbage was 1.1307, given the other factors are held constant. If onion price was to increase by $1 \%$, the multinomial log-odds of preferring for tomato relative to cabbage would not be expected to change by 1.1307 units while holding all other factors in the model constant.

\subsubsection{Onion Relative to Cabbage}

Gender was positive and statistically insignificant at $10 \%$ level of significance with $\mathrm{P}$-value 0.328 which greater than 0.1 level of significance. This is the multinomial logit estimate comparing gender for onion relative to cabbage given the other factors in the model are held constant. The multinomial logit of gender for choosing tomato relatives to cabbage was 0.5559 units high for not preferring onion to cabbage given all other factors in the model are held constant. In other words, a male was not more likely to prefer tomato relative to cabbage.

Education was negative and statistically significant at $10 \%$ level of significance with P-value 0.094 which less than 0.1 level of significance. This is the multinomial logit estimate comparing customer with formal education to customer with no formal education for choosing onion relative to cabbage was -0.4498 given the other factors in the model are held constant. A customer with form education may prefers onion relative to cabbage would be expected to change by -0.4498 units while holding all other factors in the model constant. In other words, customer with formal education was less likely to prefer onion relative over cabbage in given that all other factors remained constant. These findings support the study [23] that, customers with education may prefers less to buy fresh tomato over the cabbage because those customers may opt to use tomato sourceage.

Marital status was negative and statistically significant at $10 \%$ level of significance with P-value 0.061 which less than 0.1 . Marital status was statistically significant. This is the multinomial logit estimate comparing married customer to unmarried customer for onion relative to cabbage was 0.4975 , given the other factors in the model are held constant. The multinomial logit for married customer relatives to unmarried customer was -0.4975 units not less for preferring onion to cabbage given all other factors in the model are held constant. In other words, married customer were less likely than unmarried customer to prefer onion relative to cabbage. A married customer was less likely to choose onion relative to cabbage than unmarried customer. This may be explained that married couple prefers less onion retaive to cabbage [23] due to onion alone or with food of rice/maize can't meet household food meal but at least cabbage or cabbage with food of rice/maize flour can meet the meal when combine with food of rice or maize flours.

Tomato price was negative and statistically insignificant at $10 \%$ level of significance with P-value 0.373 which greater than 0.1 level of significance. This is the multinomial logit estimate of price for onion relative to cabbage was -0.9067 given the other factors in the model are held constant. If onion price increases by $1 \%$, the multinomial log-odds of preferring for onion relative to cabbage would not be expected to change by -0.9067 units while holding all other factors in the model constant.

Cabbage price was positive and statistically insignificant at $10 \%$ level of significance with P-value 0.765 which greater than 0.01 level of significance. This is the multinomial Logit estimate of cabbage price for onion relative to cabbage was -2345 given the other factors are held constant. If price of cabbage was to increase by $1 \%$, the multinomial log-odds of preferring for onion relative to cabbage would be expected to change by -0.2345 units while holding all other factors in the model constant.

Onion price was negative and statistically significant at $10 \%$ level of significance with P-value 0.010 which less than 0.01 level of significance. This is the multinomial Logit estimate of onion price for onion relative to cabbage was -3.9499 , given the other factors are held constant. If onion price was to increase by $1 \%$, the multinomial log-odds of preferring for onion relative to cabbage would be expected to change by 3.9499 units while holding all other factors in the model constant. In other word, as price of the onion increases by $1 \%$, the customer may less prefers onion over cabbage by 2.9499 
units. This means when price of onion increase the customers may less prefers onion relative to cabbage [22] due to consumers can't consumer only onion but cabbage may be consumed alone. Although, onion and cabbage may be consumed uncooked but possibility for onion to consume raw or uncooked is less preferred. Thus, consumers or customers had less preferred to choice onion relative to cabbage.

\section{Conclusions and Policy Recommendations}

This paper stressed to examine the effect of market price on the choice of selected fresh vegetables across major markets in Morogoro Municipality namely Mawenzi, Mazimbu, and Saba saba markets as study areas, Tanzania. The overall conclusion is that, the findings shown that effect of price on choosing fresh vegetable in the market had indicated that customers with formal education who might prefer onion to cabbage would be expected to change by 0.4498 units $(44.98 \%)$. On the other hand, married customers less prefered onion to cabbage by 0.4975 units $(49.75 \%)$. The married customers were less likely to choose onion than cabbage than unmarried customers. Therefore, these findings of the study would be used to raise awareness among policy makers, regarding the choice of vegetable associated with price factors in selected markets. This will enable coming up with relative policies to address the desired effect with the aim of stablizing price of vegetable. Based on the findings of this study, the policy recommendations are as follows: Firstly, the policy message that can be derived from this finding is that policy makers need to improve the institutional environment in the crop markets in order to stabilize vegetable price. Policy makers should continue to improve the institutional environment and business environment by enacting friendly laws to crop value chain. Secondly, government through market leadership should set reasonable security and market fee on vegetable sellers in order to create uniqueness among the vegetable market. There should be well established communication channel among the markets so that to avoid information asymmetry. Thirdly, government and non-government should train vegetable sellers on maintaining quality vegetables so as to increase knowledge and skills for improving their business in order to increase satisfy customers or vegetable consumers.

\section{References}

[1] Acharya, S. S \& Agarwal, N. L (1994), Agricultural Price Analysis and Policy. New Delhi, India: Oxford and IBH Publishing Co. Pvt. Ltd., (Chapter 6).

[2] Albayrak, N (1998). Wheat supply response: Some evidence on aggregation issues. Development Policy Review 16: 241-263.

[3] Ashomogo, G. C and Lazaro, E. A (1989). "Vegetable market in Mgeta, Morogoro District" Franco-Tanzanian horticulture Development Project, Sokoine University of Agriculture, Morogoro, Tanzania. 128 pp.
[4] Blein, R \& Longo, R (2009), Food price volatility. How to help smallholder farmers manage risk and uncertainty. Discussion Paper for Round Table 1, International Fund for Agricultural Development.

[5] Cernansky R (2015). The rise of Africa's super vegetables. Nature 522: 146-148.

[6] Chweya J. A and Eyzaguirre P. B (1999). (Eds.) The Biodiversity of Traditional Leafy Vegetables. International Plant Genetic Resources Institute, Rome Italy.

[7] Commons, J. R (2000), The definition of price, in (ed.) American Economics (Research in the History of Economic Thought and Methodology, Volume 18 Part 2) Emerald Group Publishing Limited, pp. 309-334.

[8] Diakosawas, D and Kirkpatrick, C (1990). "Exchange-Rate Policy and Agricultural Exports Performance in Sub Saharan Africa: Development Policy Review," (SAGE, London, Newbury Park and New Delhi), Vol. 8, pp. 29-42.

[9] Elster, J. Ed (1986). Rational Choice. Oxford: Basil Blackwell.

[10] Engel, J (1995). Consumer Behavior. International ed. ed. Florida: Dryden.

[11] Engel, J. F (1968). Consumer Behavior. New York: Holt, Rinehart and Winston.

[12] FAO (2005). The state of food insecurity in the world: Monitoring progress towards World Food Summit and Millennium Development Goals.

[13] FAO (2012). Save and Grow: A policymaker's guide to the sustainable intensification of smallholder crop production. Rome, Italy.

[14] Gujarati, D. N. (2004), Basic Econometrics (4th ed.). New York: McGraw Hill, Inc.

[15] Gustavsson, J., C. Cederberg, U. Sonesson, R. Van Otterdijk, and A. Meybeck. (2011). "Global Food Losses and Food Waste: Extent Causes and Prevention." United Nations, Food and Agriculture Organization. Rome, Italy.

[16] Hirsch, R. (2013). The peasants way - Initiatives to support peasant agriculture. In: Fanfest, Rosia Montana, Romania, August 17, 2013.

[17] Homans, G. (1961). Social Behaviour: Its Elementary Forms. London: Routledge and Kegan Paul.

[18] Khan, N. Ruqia, B. Hussain, J. Jamila, N. Ur Rahman, N. And Hussain, S. (2013). Nutritional Assessment and Proximate Analysis of Selected Vegetables from Parachinar Kurram Agency. American Journal of Research Communication volume 1.

[19] Kingu, J (2014). Trade liberalization and export performance in Tanzanian Cashew Nuts. Journal of Economics and Sustainable Development. ISSN 2222-1700. ISSN 2222-2855. Vol. 5, No. 3, 2014.

[20] Makokha, A. O and Ombwara, F. K (2002). Challenges and Opportunities in commercial production of indigenous vegetables in Kenya. In: Wesonga JM et al (Eds). Proceedings of the Second Horticultural Seminar Sustainable Horticultural Production in the Tropics. Juja Kenya. 
[21] Massey, P (2000). Market Definition and Market Power in Competition Analysis: Some Practical Issues. The Economic and Social review, Vol 31, No. 4, PP. 309-328.

[22] Mgeni, C. P and Temu, A. E (2010). Economic Analysis of Fresh Fruit and Vegetable Export Marketing Channels by Small-Scale Farmers in Tanzania: The Case of Meru District. Tanzania Journal of Agricultural Sciences. Vol. 10, No. 1, 4654.

[23] Mgeni, C. P. (2009). Economic Analysis of Fresh Fruit and Vegetable Export Marketing Channels by Small-Scale Farmers in Tanzania: The Case of Arumeru District. Dissertation for award of MSc Degree at Sokoine University of Agriculture, Morogoro, Tanzania. 107 pp.

[24] Mold, A., \& Prizzon, A (2010). "Fragile states, commodity booms and export performance: analysis of the Sub Saharan African case". Ideas. repec.org/p/rsceui/2010-21 html.

[25] Nyange D., Duma, T. and Temu, A. E (2000). Fresh Fruit Marketing in Tanzania: Prospects for International Marketing. In Cases and Research in Agricultural Marketing and Agribusiness. FAO. 119 pp.

[26] Oirschot Q, Westby A and Tomlins K (2003). Food Africa: Improving Food Systems in sub-Saharan Africa. Responding to a changing environment. Food Africa Workshop, aounde Cameroon.

[27] Putter, H. de., van Koesveld, M. J and de Visser, C. L. M (2007). Overview of the vegetable sector in Tanzania.

[28] Roemer, J (1988). Free To Lose. London: Radius.
[29] Rweyemamu, D. (2003). "Reforms in the agricultural sector: The Tanzanian xperience". A paper submitted to GDN under the Global Development Award Competition 2003. Agricultural Reforms and Rural Development in LICs Economic and Social Research Foundation, Tanzania.

[30] Shafer, W and Sonnenschein, H (1982). 'Market Demand and Excess Demand Functions', in K. Arrow and M. Intrilligator (eds.), Handbook of Mathematical Economics. Amsterdam: North Holland, 2, 671-693.

[31] Solomon, M (2006). Consumer Behaviour: A European Perspective. 3rd ed. Harlow: Prentice Hall

[32] The United Republic of Tanzania (2002). "The economic survey 2002. The Ministry of Finance and Economic Affairs". Dar es salaam, Tanzania. Government Printing Office.

[33] The United Republic of Tanzania (2010). "The economic survey 2010. The Ministry of Finance and Economic Affairs". Dar es salaam, Tanzania. Government Printing Office.

[34] Thompson, C. (2004). A Logistics Perspective: Being a Preferred Supplier. A guide to help you become and stay a preferred supplier to your customers. Customer Centricity. Months or years). http://www.customercentricity.biz site visited on 10/08/2016.

[35] Worldbank (2005). Agriculture can be an engine of growth in Sub-Saharan Africa World Development Report: Agriculture for Development. Washington Dc, USA.

[36] Wright, E. O (1989). 'Rethinking The Concept of Class Structure'. In The Debate on Classes. Edited by E. O. Wright and others. London: Verso. 